\title{
Impactos causados pela pandemia do Covid-19 no sistema de produção e comercialização de café: um estudo de uma empresa familiar no sul de Minas Gerais
}

\author{
Impacts of the Covid-19 pandemic on the coffee production and marketing system: a study of a \\ family business in south Minas Gerais \\ Impactos de la pandemia Covid-19 en el sistema de producción y comercialización de café: estudio \\ de una empresa familiar del sur de Minas Gerais
}

Recebido: 14/10/2021 | Revisado: 23/10/2021 | Aceito: 26/10/2021 | Publicado: 29/10/2021

Agda Silva Prado
ORCID: https://orcid.org/0000-0003-4239-4733
Instituto Federal de Educação, Ciência e Tecnologia do Sul de Minas Gerais, Brasil
E-mail: agda.prado@ifsuldeminas.edu.br
Mônica Carvalho Alves Cappelle
ORCID: https://orcid.org/0000-0002-0095-3405
Universidade Federal de Lavras, Brasil
E-mail: edmo@ufla.br
Tiago Teruel Rezende
ORCID: https://orcid.org/0000-0001-8389-2582
Universidade José do Rosário Vellano, Brasil
E-mail: tiago.rezende@unifenas.br

\begin{abstract}
Resumo
Para evitar a contaminação da COVID-19 entre os seres humanos, faz-se necessário além de aumentar as práticas de higiene, realizar utilização de máscaras e o distanciamento social. Tudo isso implica em mudanças no trabalho, consumo, emprego e economia. Muitas empresas estão inviabilizadas de produzir e comercializar para não causar aglomerações, consequentemente a falta de produção e venda estão levando a diminuição de renda. Isso impacta todos os setores de produção, tanto urbanos e quanto rurais. Este trabalho objetiva investigar os efeitos da pandemia do COVID-19 no sistema de produção e comercialização de café cultivado por uma empresa familiar do setor cafeeiro instalado no município de Santa Rita do Sapucaí, Minas Gerais. Utilizando-se como método de investigação a entrevista narrativa, conclui-se que os gestores do empreendimento estão adotando de maneira regular as técnicas de prevenção do COVID-19; a pandemia impactou no negócio em vários aspectos positivos e negativos, dentre eles, provocou vários desafios a serem enfrentados para permanecer no mercado e reorganizar o trabalho desenvolvido pelos funcionários; e como pontos positivos, a empresa foi direcionada a focar seu negócio para os cafés que produzem, na prestação de serviços e divulgação da marca.
\end{abstract}

Palavras-chave: Impacto do Covid-19; Pandemia; Cafeicultura; Agricultura familiar; Cafeteria.

\begin{abstract}
To avoid COVID-19 contamination among humans, it is also necessary to increase hygiene practices, the use of masks and social distancing. All of this implies changes in work, consumption, employment and the economy. Many companies are unable to produce and market to avoid causing agglomerations, so the lack of production and sales is causing a decrease in income. This impacts all production sectors, both urban and rural. This work aims to investigate the effects of the COVID-19 pandemic on the production and marketing system of coffee grown by a family business in the coffee sector installed in the municipality of Santa Rita do Sapucaí, Minas Gerais. Using the narrative interview as a research method, concluded that company managers are regularly adopting COVID-19 prevention techniques, the pandemic affected the business in several positive and negative aspects, among them, it caused them to face several challenges to stay in the market and reorganize the work carried out by employees; and as a positive points, the company was directed to focus your business for the coffees they produce, in the provision of services and brand promotion.
\end{abstract}

Keywords: Impact of Covid-19; Pandemic; Coffee Growing; Family farming; Coffee shop.

\section{Resumen}

Para evitar la contaminación por COVID-19 entre los seres humanos, es necesario, además de incrementar las prácticas de higiene, el uso de máscaras y distancia social. Todo esto implica cambios en el trabajo, el consumo, el empleo y la economía. Muchas empresas son incapaces de producir y vender para no generar aglomeraciones, por lo que la falta de 
producción y ventas está provocando una disminución de los ingresos. Esto impacta a todos los sectores productivos, tanto urbanos como rurales. Este trabajo tiene como objetivo investigar los efectos de la pandemia COVID-19 en el sistema de producción y comercialización del café cultivado por una empresa familiar del sector cafetero ubicado en el municipio de Santa Rita do Sapucaí, Minas Gerais. Utilizando la entrevista narrativa como método de investigación, se concluye que los gerentes de proyecto están adoptando regularmente técnicas de prevención de COVID-19; la pandemia impactó al negocio en varios aspectos positivos y negativos, entre ellos, provocó que se enfrentaran varios desafíos para permanecer en el mercado y reorganizar el trabajo que realizan los empleados; y como puntos positivos, se encaminó a la empresa a enfocar su negocio para los cafés que produce, en brindar servicios y promover la marca.

Palabras clave: Impacto de Covid-19; Pandemia; Cultivo de café; Agricultura familiar; Cafetería.

\section{Introdução}

Segundo o Ministério da Saúde (2020a), os coronavírus são uma grande família de vírus comuns em muitas espécies diferentes de animais, incluindo camelos, gado, gatos e morcegos. Raramente, os coronavírus que infectam animais podem infectar pessoas, como exemplo do MERS-CoV e SARS-CoV. Em dezembro de 2019, houve a transmissão de um novo coronavírus (SARS-CoV-2), o qual foi identificado em Wuhan na China e causou a COVID-19, sendo em seguida disseminada e transmitida pessoa a pessoa.

Os sintomas da COVID-19 podem variar de um resfriado, a uma Síndrome Gripal-SG, até uma pneumonia severa. A transmissão acontece de uma pessoa doente para outra ou por contato próximo por meio de: toque do aperto de mão contaminadas; gotículas de saliva; espirro; tosse; catarro; e, objetos ou superfícies contaminadas, como celulares, mesas, talheres, maçanetas, brinquedos, teclados de computador etc (Ministério da Saúde, 2020a). Uma pandemia é caracterizada como um surto global de uma doença, ocorrida quando um novo vírus passa a infectar pessoas, podendo se espalhar de maneira sustentável. Como não há imunidade pré-existente contra o coronavírus, sua contaminação ocorre pelo mundo inteiro (Sistema Mineiro de Inovação, 2020). Com o objetivo de evitar a contaminação da população mundial, no dia 11 de fevereiro de 2020, a Organização Mundial de Saúde (OMS) declarou a pandemia pelo novo coronavírus (COVID-19), recomendando assim o distanciamento social, a quarentena e o isolamento dos pacientes confirmados para SARS-CoV-2. Dessa forma, os países têm adotado medidas de saúde pública, como a contenção, mitigação e supressão (Baron et al., 2020).

A contenção permite a adoção de deliberações que limitam a propagação de um patógeno em focos bem definidos como na identificação e isolamento de pacientes infectados, rastreamento de contatos e quarentena de pequenas áreas, onde os casos apareceram para quebrar a cadeia de transmissão. A mitigação é adotada quando o vírus se propaga rapidamente e há transmissão local sustentada, impossibilitando o isolamento de todos os casos, isso envolve o fechamento de escolas e o banimento de eventos com aglomeração social, para evitar sobrecarga ao sistema de saúde e aumento de casos que necessitam de terapia intensiva. A supressão é uma medida de distanciamento social intensivo e em larga escala que visa suprimir a transmissão rápida e minimizar os casos de morte em curto prazo (Baron et al., 2020).

O Brasil registrou o primeiro caso de COVID-19 em 26 de fevereiro de 2020, e a primeira morte em 20 de março de 2020. No dia 20 de abril de 2020 o governo brasileiro decreta o estado de calamidade pública no país em razão da pandemia de coronavírus até o dia 31 de dezembro de 2020. Este reconhecimento de calamidade pública permite que o governo aumente o gasto público e descumpra a meta fiscal prevista para o ano de 2020 (Baron et al., 2020; Decreto Legislativo nº 6, 2020 ; Ministério da Saúde, 2020b).

O grande volume de casos confirmados, de mortes e o colapso do sistema de saúde resultou no chamado lockdown, uma medida imposta pelo estado e que envolve a interrupção de atividades econômicas não essenciais e frequentemente restrições na mobilidade. Assim, as pessoas circulam nas ruas unicamente para a compra de alimentos e medicamentos, ou para trabalhar, no caso de profissionais da saúde (Baron et al., 2020; Silva et al., 2020). 
Podemos considerar que desde a identificação dessa doença, a população vive em um cenário em que as restrições de circulação da população e cuidados para evitar o contágio pelo COVID-19 foram necessárias. Consequentemente, esse cenário pôde causar mudanças no hábito de consumo e compra dos cidadãos, pois os estabelecimentos que fazem parte das atividades econômicas não essências, foram obrigados a interromper seu funcionamento, causando diminuição de seus faturamentos. São ciclos constantes de causas e efeitos, se as firmas não conseguem oferecer seus produtos e serviços ao mercado, automaticamente ela não é remunerada e consequentemente não consegue quitar suas dívidas. Isso pode levar a demissão de funcionários, que por sua vez perdem seu poder de compra pela falta de um trabalho remunerado.

Os impactos causados pela pandemia de Covid-19, causada pelo vírus SARS-CoV-2 ou Novo Coronavírus, além de provocar repercussões de ordem biomédica e epidemiológica em escala global, provoca impactos sociais, econômicos, políticos, culturais e históricos sem precedentes na história recente das epidemias (Sistema Mineiro de Inovação, 2020). Pode-se considerar um efeito dominó em todas cadeias produtivas sejam elas industriais, alimentares ou de serviços. Causando impactos no poder de compra do consumidor e consequentemente nos hábitos de consumo.

Além dos danos à saúde que a COVID-19 causa à população, o fechamento de empresas devido recessão econômica, também é acometido pela pandemia, e agravando o aumento no número de desempregados. Segundo dados do Instituto Brasileiro de Geografia e Estatística (IBGE), 40\% das empresas que fecharam as portas em junho de 2020, tiveram suas atividades encerradas por causa da pandemia do novo coronavírus. As empresas de pequeno porte e aquelas que fazem parte do seguimento de prestação de serviços, são as que tiveram um maior percentual de fechamento (Uol, 2020).

Para Barros (2020), o segundo trimestre de 2020 foi considerado o período auge do distanciamento social realizado para controlar a pandemia do COVID-19. Nesse mesmo período, o IBGE realizou um levantamento do Produto Interno Bruto (PIB) gerado pelo Brasil. O PIB se refere a soma dos bens e serviços produzidos no Brasil, em termos monetários, somou R\$1,653 trilhão de abril a junho. Em comparação ao primeiro semestre de 2020, esse valor representa uma queda de 9,7\% do valor gerado no primeiro trimestre, e realizando uma comparação com o segundo trimestre de 2019, essa queda na produção chegou a 11,4\%.

Segundo dados do Instituto Brasileiro de Geografia e Estatística (2020), um dos setores que contribuíram para o amortecimento da queda do PIB, foi o setor agropecuário, segundo relatório emitido pelo Instituto, a agropecuária cresceu 0,4\% no segundo trimestre. Um dos setores que contribuíram positivamente, foi a cafeicultura, com aumento de 18,2\%. A produção de soja e arroz também contribuíram positivamente com aumentos de 5,9\% e 7,3\% respectivamente.

A Organização Internacional do Café (OIC), buscou levantar dados da demanda, consumo e produção de café ao redor do mundo. Essa análise é baseada em uma amostra dos 20 principais países consumidores de café, que representam $71 \%$ da demanda global, cobrindo o período 1990-2018. Como resultado principal, verificou-se que o número de consumo fora de casa está caindo de maneira expressiva no curto prazo, devido aos fechamentos de cafeterias e padarias em vários lugares do mundo. Mas por outro lado o consumo do lado do varejo, ou seja, o consumo doméstico, vem aumentando (International Coffee Organization, 2020a).

Esse aumento foi registrado nas primeiras semanas da crise. Impulsionado principalmente pelas vendas nos supermercados, resultante da compra e do estoque de pânico e da substituição do consumo fora de casa pelo consumo interno, em virtude de medidas de distanciamento social. Uma recessão global iminente poderá impactar negativamente o consumo geral de café. Mas acredita-se que a demanda por itens alimentares como café tende a ser relativamente inelástica, e os efeitos colaterais da demanda provavelmente se materializarão com um atraso de tempo, dependendo do nível de poupança das famílias e redes de segurança social (International Coffee Organization, 2020b).

Diante das causas econômicas e sociais que a pandemia está provocando no país e no mundo; pela retomada cautelar do comércio; pelas recentes pesquisas que norteiam esse assunto, mas poucas focadas no agronegócio e em especial no setor 
cafeeiro, a pergunta de pesquisa que norteia esse trabalho é: quais são os impactos causados pela pandemia do COVID-19 em uma empresa atrelada ao setor cafeeiro?

Analisar o impacto da pandemia no setor agropecuário e, em especial, na cafeicultura é de extrema relevância, pois a economia do pais é predominantemente agrícola e o Brasil é o maior produtor de café mundo. Assim, quanto mais estudos forem realizados com esse objetivo, maiores serão as possibilidades de traçar estratégias para fortalecer o setor.

É por esse motivo que o presente estudo possui como objetivo geral investigar os efeitos da pandemia do COVID-19 no sistema de produção e comercialização de café cultivado por uma empresa familiar do setor cafeeiro instalado no município de Santa Rita do Sapucaí, Minas Gerais. Como objetivos específicos, analisou-se: quais as adaptações realizadas no sistema de produção e comercialização de café como práticas para prevenção da doença; os impactos causados pela COVID-19 no convívio, rotina e comunicação entre a equipe de trabalho; como a pandemia está interferindo na comercialização de cafés; qual a nova rotina adotada pelos gestores do negócio; e pontos positivos e negativos causados pela pandemia.

Espera-se que este estudo possa ser utilizado como referência para os demais negócios do seguimento agropecuários e como suporte para orientação na adoção de estratégias e tomadas de decisão. A seguir, será apresentada a metodologia do estudo e posteriormente, apresenta-se os resultados obtidos pelo empreendimento. Por fim, serão apresentadas as conclusões e os pontos para reflexão e propostas para explorar este assunto em demais pesquisas sobre esse tema.

\section{Metodologia}

Essa pesquisa caracteriza-se por natureza qualitativa e foi desenvolvida mediante um roteiro semiestruturado de entrevista e pesquisa documental. Devido ao distanciamento social exigido pelo COVID-19, as entrevistas foram realizadas com a gestora do empreendimento nos dias 23 de julho, 19 e 25 de agosto de 2020 por uma reunião virtual e conversas via aplicativo de mensagem, em que todo conteúdo foi gravado e transcrito. A pesquisa documental foi feita no material digital produzido pela empresa, como site, notícias indexadas e redes sociais. Para preservar a identidade da empresa e de seus respectivos gestores, os nomes reais foram substituídos por nomes fictícios.

A transcrição das informações faz-se necessária, pois, de acordo com Bauer e Gaskell (2011), características paralinguísticas, tais como o tom da voz ou as pausas, são transcritas a fim de que se possa estudar a versão da história não apenas quanto ao seu conteúdo, mas também quanto a sua forma retórica. Por mais trabalhosa e monótona que uma transcrição venha a ser, ela é útil para a compreensão do material e propicia um fluxo de ideias para interpretar o texto.

O método de entrevista utilizado para investigar a o problema de pesquisa, foi a entrevista narrativa. Segundo Bauer e Gaskell (2011), a narrativa proporciona remeter a lembranças de acontecimentos, a colocar as antigas experiências em sequência e encontrar possíveis explicações para cada uma, além de jogar com a cadeia de acontecimentos que constroem a vida individual e social. A narração de um acontecimento pode ser traduzida tanto em termos gerais como em termos indexados. Essa indexação é referenciada e feita a acontecimentos concretos em um lugar e em um tempo.

Além disso, é um método qualitativo de pesquisa que se caracteriza por abordar questões relacionadas às singularidades do campo e dos indivíduos pesquisados. As entrevistas narrativas são mais apropriadas para captar histórias detalhadas, experiências de vida de um sujeito ou de poucos sujeitos. Deve-se passar um tempo considerável com cada entrevistado e captar informações por meio de diferentes tipos de fontes, que podem ser de origem pessoal, familiar ou social. Alguns exemplos são cartas, fotografias, documentos, correspondências, diários, entre outros (Muylaert et al., 2014). No presente estudo, os materiais utilizados foram as plataformas virtuais da empresa. 
"A entrevista narrativa se processa através de quatro fases: ela começa com a iniciação, move-se através da narração e da fase de questionamento e termina com a fase da fala conclusiva” (Bauer \& Gaskell, 2011, p. 96).

Para Zaccarelli e Godoy (2013), o uso das metodologias centradas nas narrativas tem produzido um importante e relevante corpo de conhecimentos diferenciado em relação a outras possibilidades de análise das organizações. Dessa forma, a entrevista narrativa é um importante instrumento para analisar os impactos que a COVID-19 está provocando nas empresas.

O método analítico utilizado para a entrevista narrativa foi a análise temática, que constitui um procedimento gradual de redução do texto qualitativo, assim as unidades do texto são progressivamente reduzidas em duas ou três rodadas de séries de paráfrases (Bauer \& Gaskell, 2011). A partir daí, desenvolveu-se um sistema de categorias permitindo a codificação do texto. A codificação será apresentada nos resultados e está atrelada conforme os objetivos específicos propostos deste trabalho.

A análise temática consiste em descobrir os núcleos de sentido que compõem uma comunicação cuja presença ou frequência signifiquem alguma coisa para o objetivo analítico visado. Desdobra-se em três etapas: 1- Pré-análise: consiste na escolha dos documentos a serem analisados; 2 - Exploração do material: recorte do texto, escolha das regras de contagem e classificação e agregação dos dados; 3 - Tratamento dos resultados obtidos e interpretação (Cappelle et al., 2003; Minayo, 2000).

Para Zaccarelli e Godoy (2013), quando se trata de mudanças na cultura organizacional, as histórias informam a respeito tanto da retórica gerencial quanto das normas não explicitadas, possibilitando capturar a complexidade que envolve tais processos. Elas ajudam na compreensão de como significados atribuídos à mudança organizacional tornam-se dominantes, examinando-se também a oposição do diálogo local versus os monólogos gerenciais ou o que se pode chamar de "grandes histórias".

Como a análise temática proporciona a condensação da entrevista em núcleos de sentidos (Bauer \& Gaskell, 2011; Cappelle et al., 2003; Minayo, 2000), os objetivos específicos dessa pesquisa foram considerados como os núcleos de sentido, os quais foram utilizados para categorizar os resultados: verificar quais foram as adaptações realizadas no sistema de produção e comercialização de café como práticas para prevenção da doença; impactos causados pela COVID-19 no convívio, rotina e comunicação entre a equipe de trabalho; como a pandemia está interferindo na comercialização de cafés; qual a nova rotina adotada pelos gestores do negócio; pontos positivos e negativos causados pela pandemia.

Para Bauer e Gaskell (2011), toda pesquisa com entrevistas não significa ser um processo de informação de mão única passando de um (o entrevistado) para outro (o entrevistador). Ela faz parte de um processo de interação, uma troca de ideias e de significados, em que várias realidades e percepções são exploradas e desenvolvidas. Assim, toda entrevista é um processo social, uma interação ou um empreendimento cooperativo, em que as palavras são o meio principal de troca.

O objeto de estudo desta pesquisa é um empreendimento do setor cafeeiro constituído por uma propriedade cafeeira e uma cafeteria localizados no município de Santa Rita do Sapucaí, sul do estado de Minas Gerais, em uma região denominada como Mantiqueira de Minas.

\subsection{História do objeto de estudo}

Sua história inicia-se quando o proprietário da fazenda cafeeira a adquire em 1969, com o intuito de passar sua aposentadoria vivendo exclusivamente do café. Porém, quando este sonho estava prestes a se concretizar, o proprietário foi diagnosticado com Alzheimer.

A partir daí, algumas propriedades já adquiridas foram vendidas para custear o tratamento e, antes de vender a última parte onde está instalada a casa sede da propriedade, o filho do proprietário solicitou a sua mãe para que o permitisse assumir a gestão do restante das terras. E se, em um período de cinco anos, a fazenda não gerasse lucros, a propriedade poderia ser vendida. A propriedade está sob a gestão do filho desde 2010. 
Em 2011, a propriedade obteve a primeira certificação do programa do estado de Minas Gerais, chamada de "Certifica Minas”, promovida pela EMATER/MG (Empresa de Assistência Técnica e Extensão Rural do Estado de Minas Gerais). Outra iniciativa tomada foi a realização de vários cursos voltados para o meio rural promovidos pelo SENAR/MG (Serviço Nacional de Aprendizagem Rural). Conforme relato da gestora, esposa do gestor da propriedade:

“[...] e ai a gente fez os cursos do SENAR e dali pra frente não parou mais, a gente tem 'isso aqui' de curso do SENAR, doceira, tratorista, apiário, a gente tem tudo que o SENAR oferece."

Antes de se dedicar totalmente e assumir a gestão da propriedade, o filho do proprietário residia em Nova York, ficava 6 meses fora e 6 meses no Brasil, já vivia no exterior por um período de 20 anos.

Foi então que, em 2013, o casal de gestores ainda namorados resolveu assumir o negócio juntos e resgatar esse tão sonhado plano do proprietário de possuir uma propriedade de café. Assim, a gestora assumiu junto com o filho do proprietário a responsabilidade do negócio, através de um convite para largar o antigo trabalho e se dedicar totalmente ao café. Em 2013 , a gestora montou o site do empreendimento e, em 2014, foi realizado o registro da marca.

Segundo a gestora:

"Porque era uma conexão que ele tinha com o pai, a fazenda então para ele era uma questão de... não era questão de tipo: eu preciso disso para viver, é uma conexão, eu tô conectado no meu pai através desse sonho que ele tinha e eu quero manter isso vivo!"

Em 2015, após realizar várias tentativas de comercialização de seus cafés para cafeterias e pontos de comercialização, foi lançado a coffee bike, uma bicicleta com uma estrutura adaptada para preparar e comercializar os cafés, essa bicicleta é utilizada principalmente em eventos para divulgar a marca.

"E aí o negócio virou uma febre né. Todo mundo queria uma franquia dessa bike pra vender cafés, e ai a gente começou aparecer em programa de TV, dar entrevista, falar sobre o café, e aí o povo começou a vir atrás da gente: 'eu quero esse café, esse café pra vender",".

Hoje a fazenda possui 16 alqueires (tamanho equivalente a 38,7 hectares) e uma produção anual equivalente a 350 sacas de café. Neste mesmo local, há uma torrefação onde se torra o café com a marca própria e para terceiros, também uma cozinha utilizada para produção de doces e para cursos. Tal espaço é considerado como uma cozinha colaborativa, pois, se alguém tiver o interesse de iniciar um negócio, mas não tem condições na própria casa, o local fica à disposição para ser alugado e dar início a produção ali.

Vale destacar, que a cozinha colaborativa surgiu através da percepção da gestora de como as mulheres que trabalhavam no período da colheita ficavam depressivas quando esse serviço acabava. Assim, a primeira confecção e venda de doces realizados por essas mulheres, oportunizou a aquisição de embalagens e rótulos para a venda do café torrado e moído - na época o café era torrado de maneira artesanal por uma das famílias parceiras, utilizando o torrador de bola.

Atualmente, a fazenda está passando por um processo de revitalização da lavoura, então, a média de produção está abaixo do esperado, mas a perspectiva é que, com toda a lavoura reformada, essa produção atinja patamares maiores.

A empresa chegou a exportar $30 \%$ de sua produção, mas, atualmente, o foco é em promover os cafés de qualidade e a marca no país. Além da fazenda, a empresa conta com uma estrutura de duas cafeterias, uma localizada no município de Santa Rita do Sapucaí/MG e outra em Santos/SP e duas coffee bikes que são suportes para eventos. 
A primeira cafeteria foi inaugurada em 2017, após três anos de lançamento da marca. O ponto comercial se originou a partir dos pedidos de franquia da coffee bike, mas, para os gestores, proporcionar uma franquia de bike, seria uma tarefa difícil de gerir, pois a bike é um empreendimento itinerante. Então, a cafeteria foi montada para promover o crescimento da marca e a aproximação com os clientes, isso resultou em um movimento muito acima do esperado.

Posteriormente, alugou-se um novo ponto comercial anexo aos fundos da cafeteria. Esse espaço se tornou um lounge, ou seja, um espaço para as pessoas apreciarem o café e os produtos comercializados pela cafeteria.

Todo o café é comercializado nacionalmente pela da cafeteria, pelo site, na venda para o consumidor final em eventos, através da coffee bike, por meio de empórios, de outras cafeterias, restaurantes e pelo mercado de commoditie. Duas linhas de cafés torrado e moído são produzidas: a linha premium, considerada uma linha de cafés de melhor qualidade e com valor agregado, e a linha tradicional comercializada a preço popular.

Diversos produtos à base de café são comercializados e produzidos pela empresa, como licores, cervejas, geleias e chás. Utilizando além do fruto do café como matéria prima, também a sua casca, preparada em um processo que origina a cascara do café (do termo casca, na língua espanhola). É a casca do fruto cereja do café desidratada (Menocci, 2020). Conforme relatado pela gestora:

“E a nossa cafeteria é o nosso 'show room' pra vender os cafés pras cafeterias, então a gente apostou que ter a torrefação pra gente e também para comunidade, pra ajudar o pessoal, que quer vender o café para o mercado, né."

A administração do negócio é dividida da seguinte maneira entre o casal de gestores: o gestor, filho do dono da propriedade, é responsável pela fazenda e todos os assuntos relacionados à produção de café na lavoura, e a gestora, sua esposa, é responsável pela administração da cafeteria de Santa Rita do Sapucaí e comercialização dos produtos. A cafeteria localizada em Santos está sobre a gestão do filho do primeiro casamento do gestor. O casal possui 4 filhos ao todo, 3 são do primeiro relacionamento do gestor e um do primeiro relacionamento da gestora, e toda família está envolvida com o negócio.

Com o surgimento da pandemia provocada pelo novo Coronavírus, o formato das parcerias, comercialização e prestação de serviços pelo empreendimento sofreu alterações, todas elas serão relatadas a seguir conforme informações passadas pela gestora.

\section{Resultados e Discussão}

Como descrito anteriormente, o objetivo geral deste trabalho foi investigar os efeitos da pandemia do COVID-19 no sistema de produção e comercialização de café cultivado por uma empresa cafeeira familiar. E os resultados abaixo serão descritos conforme os objetivos específicos, seguindo a seguinte ordem: adaptações realizadas no sistema de produção e comercialização de café como práticas para prevenção da doença; impactos causados pela COVID-19 no convívio, rotina e comunicação entre a equipe de trabalho; como a pandemia está interferindo na comercialização de cafés; qual a nova rotina adotada pelos gestores do negócio; pontos positivos e negativos causados pela pandemia.

\subsection{Adaptações realizadas no sistema de produção e comercialização de café como práticas para prevenção da COVID-} 19

\subsubsection{Prevenção da COVID-19 no sistema de produção de café}

O início da pandemia trouxe um cenário com muitas dúvidas para os gestores a respeito de como se comportar para que não houvesse o risco de proporcionar contaminação entre as pessoas que estão envolvidas no negócio. Logo, em abril de 2020, 
foram determinadas pelo Ministério da Saúde, as primeiras medidas de distanciamento social, conforme orientações estabelecidas pela Organização Mundial de Saúde - OMS (Centro de Operações de Emergência em Saúde Pública, 2020).

O SENAR - Serviço Nacional de Aprendizagem Rural, em parceria com o Ministério da Saúde e o Ministério da Agricultura, Pecuária e Abastecimento (MAPA), criaram uma cartilha com recomendações de prevenção e combate ao COVID19. Nela, as recomendações são orientadas conforme a especificidade do trabalho rural, pois muitos trabalhadores são transportados com os veículos da empresa, outros residem na própria fazenda, os equipamentos de trabalho podem ser utilizados por mais de um funcionário e o meio rural é um espaço que sempre recebe visitações, seja de clientes ou técnicos que se deslocam para dar assistência. Por isso é extremamente importante atender as especificidades da forma como o trabalho no meio rural é realizado e saber adotar adequadamente as técnicas de prevenção (Serviço Nacional de Aprendizagem Rural, 2020).

Conforme relatado em entrevista, nesse período, os gestores optaram por preservar a saúde dos funcionários da fazenda, evitando se deslocaram até o meio rural, deixando a gestão da fazenda sobre a responsabilidade de um gerente, para a gestora: "A gente que se preocupa, porque a gente é quem vem de fora."

A prevenção de contágio é feita pelo distanciamento social, ou seja, o afastamento das pessoas para que o vírus não seja transmitido entre elas, higienização das mãos e superfícies. As técnicas de prevenção são ilustradas pelo Ministério da Saúde (2020a) e pela Organização Pan-Americana de Saúde (2020) seguindo as normas da Organização Mundial da Saúde (OMS): 1. Lavar com frequência as mãos até a altura dos punhos, com água e sabão, ou então higienize com álcool em gel $70 \%$; 2 . Ao tossir ou espirrar, cobrir o nariz e boca com lenço ou com a parte interna do cotovelo; 3 . Não tocar olhos, nariz, boca ou a máscara de proteção fácil com as mãos não higienizadas; 4. Se tocar olhos, nariz, boca ou a máscara, higienize sempre as mãos como já indicado; 5. Manter distância mínima de 1 (um) metro entre pessoas em lugares públicos e de convívio social. Evitar abraços, beijos e apertos de mãos; 6. Higienizar com frequência o celular, brinquedos das crianças e outros objetos que são utilizados frequentemente; 7. Não compartilhar objetos de uso pessoal como talheres, toalhas, pratos e copos; 8. Manter os ambientes limpos e bem ventilados; 9. Evitar circulação desnecessária nas ruas, estádios, teatros, shoppings, shows, cinemas e igrejas; 10. Se estiver doente, evite contato próximo com outras pessoas, principalmente idosos e doentes crônicos; 11 . Dormir bem e ter uma alimentação saudável; 12. Recomenda-se a utilização de máscaras em todos os ambientes.

Como o período de pandemia coincidiu com a colheita do café na fazenda, não foi possível ficar longe do local, pois a fase da colheita é um período crucial para obter homogeneidade entre os lotes de cafés colhidos e alcançar a qualidade desejada nos aspectos físicos e sensoriais do fruto (Borém, 2008). Então, os cuidados para resguardarem a equipe de trabalho na fazenda foram a utilização de máscaras, álcool em gel, e o distanciamento social, principalmente para evitar o contato das pessoas que visitam o local com a equipe de trabalho.

Tais visitas atualmente estão limitadas ao número de três pessoas por vez. A fazenda também desenvolve o trabalho de turismo rural, segundo a gestora, assim que puder retomar as atividades turísticas, irá se orientar com a vigilância sanitária da cidade sobre quais serão os devidos cuidados necessários para preservar a saúde dos funcionários e visitantes.

Os trabalhos nas lavouras e demais estruturas na propriedade, estão pulverizados entre os funcionários, segundo a gestora:

"Eles não ficam juntos, fica um no terreiro suspenso, outro no terreiro, meu marido tá limpando café, ou dá suporte pros dois, tá sempre com a máscara por perto né. E eles estão... e lá em cima no cafezal colhendo, a mãe e filha tão de um lado da lavoura e os homens tão pra outro, só que os homens tão separados, tem o filho e pai, prum lado, né. [...] Cada um tem sua casa, cada um tem sua família, eles sempre trabalham unidos em grupo de família, é melhor pra eles, entendeu? Eles fazem par com eles mesmos, eles não ficam se misturando muito, eles juntam em família. " 
Verifica-se que a preocupação que os gestores possuem em seguir as orientações para prevenção da doença é expressiva e que se preocupam com bem-estar de sua equipe, seguindo os protocolos estabelecidos pelo Ministério da Saúde (2020a) e Serviço Nacional de Aprendizagem Rural (2020).

"Porque eu não quero que... eu não quero de jeito nenhum colocar o pessoal em risco, a gente não ia conseguir ficar em paz se soubesse que a gente levou alguém lá que contaminou os nossos funcionários, né."

Vale destacar que no período da pandemia, a equipe de trabalho presente na fazenda faz parte de uma mão de obra temporária, que é contratada para executar o trabalho da colheita. E com o apoio financeiro governamental para proteger a mão de obra trabalhista, os gestores optaram por conceder o apoio tanto para os empregados permanentes da fazenda, quanto aos da cafeteria, seguindo as normas estabelecidas na MP 936 (Medida Provisória nº 936, 2020). Assim, os empregados fixos ficariam sem trabalhar, recebendo este tipo de auxílio no intuito de evitar a contaminação pelo COVID-19. O fato é que, segundo a gestora, ao invés de seus empregados ficarem em casa, optaram por receber o apoio e foram trabalhar em outros lugares de maneira informal, conforme afirmação apresentada pela gestora:

“Quando deu o auxílio pra eles, eles foram trabalhar em outro lugar. Então eles pegaram o auxílio, alguns foram para outras fazendas. Então o João falou: se eu soubesse que eles não iam ficar quietinhos em casa, eu deixava eles trabalhando e não pegava o auxílio, tanto é que eu acho que ele só deu um mês de auxílio entendeu? Porque dois funcionários foram e não voltaram."

A Medida Provisória 936 de $1^{\circ}$ de abril de 2020 (MP 936) trata-se de um Programa Emergencial de Manutenção do Emprego e da Renda. Possui como objetivos: preservar o emprego e a renda; garantir a continuidade das atividades laborais e empresariais; reduzir o impacto social decorrente das consequências do estado de calamidade pública e de emergência de saúde pública. E para o alcance desses objetivos, as ações institucionalizadas são: o pagamento de Benefício Emergencial de Preservação do Emprego e da Renda; a redução proporcional de jornada de trabalho e de salários; e a suspensão temporária do contrato de trabalho (Medida Provisória $n^{\circ}$ 936, 2020).

Apesar da atitude realizada pelos funcionários da fazenda, o Instituto de Economia Agrícola (IEA) já previa essa reação, segundo o Instituto, a utilização efetiva dependerá do balanço entre os ganhos dos trabalhadores na colheita formal e o valor do auxílio emergencial do governo federal, posto que os cafeicultores evitem o uso de mão de obra não registrada - daqueles que não desejam perder aquele auxílio - para não incorrerem em futuros passivos trabalhistas. Dessa forma, os trabalhadores têm a oportunidade de escolha em trabalhar formalmente, ficarem sem trabalhar recebendo o auxílio, ou ainda trabalhar informalmente e recebendo o benefício concedido pelo governo (Instituto de Economia Agrícola, 2020).

\subsubsection{Prevenção da COVID-19 realizada na cafeteria}

Passando a análise para a cafeteria instalada no município de Santa Rita do Sapucaí, a gestora toma todos os cuidados necessários para que não ocorra o risco de contaminação, os cuidados para prevenção da COVID-19 são relatados por ela a seguir:

"O tempo inteiro passando álcool, a gente coloca o álcool, e assim que sai pessoas a gente troca lá, limpa tudo. Tudo foi descartável até uma, acho que uma ou duas semanas atrás tudo era descartável, agora que foi liberado na loja, na cidade, eu peço pra elas passarem... a nossa máquina de expresso sai água quente, né, da caldeira. Então ela passa água tudo. No início eu usava a luva, mas fomos orientados a não utilizar, até porque a gente mexe com coisa quente é perigoso né." 
Os cuidados tomados na cafeteria não só partem da preocupação da gestora para que não ocorra a contaminação com ela, funcionários e clientes, mas também por verificar que, caso determinadas normas não forem seguidas, corre-se o risco de perder a clientela. Além disso, houve um limite estabelecido pela gestão do município para a entrada de pessoas na cafeteria, sendo limitado a no máximo de 5 pessoas no estabelecimento.

“E também porque o próprio cliente que entra e vê a gente sem máscara ele já sai, e nem ficam lá dentro, já tão com medo também, porque tá manejando o alimento deles.”

Da mesma forma como o fornecimento do auxílio para a equipe de funcionários na propriedade resultou em consequências negativas, aconteceu na cafeteria. Tal fornecimento foi promovido para as funcionárias e as mesmas solicitaram suas respectivas demissões. Das três funcionárias afastadas temporariamente recebendo o benefício, ao fim do prazo de pagamento, duas pediram demissão, a terceira permaneceu no emprego devido solicitação da gestora da cafeteria. Mesmo assim, houve a necessidade de negociação para motivar a permanência no emprego, conforme relatado, a cafeteria não está funcionando em tempo integral, mas o salário está sendo pago nesse período de pandemia como assim o fosse. Segundo opinião da gestora:

“Então, assim, eu não sei até que ponto foi bom isso, a ajuda do governo, porque eu acho que tinha que ser pensado melhor, tipo deveria ter apoiado o empresário, pra que o empresário aguentasse a pagar o salário, e a pessoa continuasse trabalhando, porque eu acho que eles se acostumaram a ficar sem trabalhar. Eu não achei benéfico com isso."

Apesar de a cafeteria buscar a prevenção da COVID-19 em prol da segurança da saúde e melhor atendimento aos clientes, muitas das pessoas que frequentavam o local, se apresentaram resistentes em adotarem as normas de prevenção, principalmente com relação à utilização da máscara, consequentemente, isso provocou a redução das vendas.

"A maior dificuldade para gente, a gente não entendia muito que tava acontecendo, o quê que era permitido, o quê que não era... Nós somos muito corretinhos assim, tipo, se não pode usar, tem que ser tudo descartável... tudo descartável! Aí o pessoal: Não, mas na cidade tão usando ai... o pessoal queria... Olha eu perdi muita venda assim: posso sentar pra tomar café aqui? Desculpe, infelizmente não pode, porque tá proibido. Eles iam embora. Eu perdi a venda, cheguei ao ponto de vender dois expressos num dia e o pessoal ficando chateado comigo porque não podia entrar e sentar no café. Como se a culpa fosse minha, sabe? Depois que passou essa fase "do não posso entrar", que começou poder entrar, pessoal entrava sem máscara e não podia [...]. Aí começou a ter máscaras para quem esquecia, aí foi o jeito que a gente encontrou.

\subsection{Impactos causados pela COVID-19 no convívio, rotina e comunicação entre a equipe de trabalho}

Como verificado anteriormente, a pandemia provocou algumas mudanças no corpo da equipe de trabalho da fazenda e da cafeteria aqui estudadas, como a inadimplência de alguns trabalhadores, desligamento voluntário de funcionárias e adoção dos protocolos para preservar a saúde de todos os envolvidos.

Apesar do desfalque de trabalhadores, a pandemia oportunizou a junção de esforços entre aqueles que se encontravam na mesma situação, como é o caso em que a fazenda, neste momento, pôde contar com o apoio de seus vizinhos para realizarem o trabalho durante a colheita de café, como exemplificado a seguir pela gestora:

"E ai é nessa hora que você começa a ver que você não está sozinho, sempre tem alguém que... né. Quando ele acaba o trabalho dele lá, ele vem pegar o café... pega o meu trator, o trator da nossa propriedade, sobe na Fazenda, recolhe todo café colhido e desce pra ajudar a gente. Então eles estão ajudando a gente, a família, o pessoal está se unindo para ajudar, porque a gente precisa de um tratorista, a gente ficou desfalcado de um dos nossos principais funcionários na pandemia." 
Já na cafeteria, a pandemia fez a gestora reorganizar o trabalho, e ela constatou que a quantidade de funcionários que existia, mesmo que o negócio volte totalmente ao normal, será possível reduzir a equipe e consequentemente realizar economia no negócio, segundo ela:

“[...] então, a pandemia ela ajudou a gente a enxugar, né. A gente enxugou a operação e viu que não precisava ter tantos funcionários, né. [...] Então a gente enxugou a operação, né.

Outro fato interessante, com a redução de mão de obra na cafeteria e a participação de apenas uma funcionária, proporcionou maior autonomia para a funcionária em desempenhar seu trabalho de maneira satisfatória. A gestora se considera confiante em delegar o trabalho para a funcionária que permaneceu na cafeteria.

"Eu acho assim: Eu tenho sorte de ter alguns funcionários que passaram por lá que são bem criativos, mais eu acho que eu tô dando mais liberdade para elas criarem, sabe. Tipo, tô sentindo mais confiança, já que eu estou com uma funcionária só. E ela tá me compreendendo, então eu tô sentindo mais confiante em deixar ela me ajudar a cuidar das redes sociais, assim cuidar... ela tirar foto, ela já sabe como que eu gosto que tire foto, ela manda bilhete... [...] eu tinha muita insegurança com isso, mas não, estou me sentindo bem segura, tanto é que ela manda para mim a propaganda na lista de transmissão, eu: Aí que gracinha!!! Tá tão bonitinha, sabe? Eu reposto coisa que ela posta na social, eu tô gostando muito. Eu tô sentindo segurança, tá me surpreendendo, eu tô ficando feliz, de ver que a coisa funciona sem eu tá lá o tempo inteiro em cima, entendeu?"

\subsection{Forma como a pandemia está interferindo na comercialização de cafés}

Como se pode observar, o presente objeto de estudo analisado trata-se de um empreendimento agropecuário do setor cafeeiro, composto por uma fazenda e uma cafeteira instalados no município de Santa Rita do Sapucaí, ambos geridos pela mesma família.

Dessa forma, pode-se considerar que esta pesquisa envolve uma instituição que é responsável por todo processo de produção em que o café é submetido, ou seja, desde o plantio de mudas até a entrega da bebida na xícara ao consumidor final.

Assim, o processo de comercialização faz parte de umas etapas mais importantes nesse trabalho, pois é fase que compila todos os esforços realizados durante o processo de produção do café, e é o momento em que se alcança o retorno financeiro de todos os investimentos realizados.

Como narrado pela gestora, pandemia provocou várias mudanças na comercialização de cafés e produtos vendidos pela empresa. Primeiramente, as vendas chegaram a alcançar um nível de apenas 5 a $10 \%$ do que era comercializado anteriormente e vários produtos alimentícios considerados como perecíveis que estavam em estoque, tiveram que ser descartados. O segundo fato, foi a queda no número de fornecedores que deixaram de entregar seus produtos que eram revendidos na loja, e por fim, a gestora suspendeu a locação de dois dos três imóveis que a empresa alugava para não se endividarem.

O primeiro passo para superar essa queda drástica nas vendas, foi a adoção de dois tipos de venda: o delivery e o take away. O delivery acontece quando a venda é realizada por encomenda e entregue no local onde o consumidor se encontra. A venda take away é quando o cliente realiza sua encomenda e a retirada do produto é feita no próprio estabelecimento. Essa estratégia de venda obteve boa aceitação dos consumidores, e segundo a gestora, é uma forma de comercialização que mesmo após esse período de pandemia, irá permanecer.

Como diagnosticado pela OIC e o IEA, o consumo doméstico aumentou durante a pandemia, isso favoreceu que a estratégia de venda como o delivery esteja obtendo boa aceitação dos clientes da cafeteria (International Coffee Organization, 2020a; Instituto de Economia Agrícola, 2020). 
A cafeteria além de fornecer os cafés com a marca própria e os produtos feitos à base de café citados no histórico da empresa, a gestora contava com 25 fornecedores, de produtos artesanais (geleias, azeite, licores, etc), bolos e quitandas para abastecer a cafeteria. De acordo com sua narração: “a minha cafeteria, a gente trabalha, tem mais de 25 fornecedores locais lá. Eu trabalho bem com marcas, eu valorizo muito o que é produzido localmente”.

Antes do surgimento da pandemia, a gestora buscava trabalhar com fornecedores residentes da cidade de Santa Rita do Sapucaí. Como o fechamento temporário do comércio foi uma das estratégias para conter o avanço da pandemia, a queda nas vendas foi uma consequência imediata e os fornecedores que a cafeteria contava, começaram a vender seus produtos diretamente para os consumidores, a um preço abaixo do que seria comercializado no estabelecimento. Isso levou a gestora da cafeteria a buscar fornecedores da região, segundo ela:

“Então as nossas vendas caíram muito, porque $90 \%$ dos meus fornecedores são da cidade, eles começaram a vender diretamente ao consumidor final. [...] Porque eu fiquei na mão... como se eu tivesse na mão de um... de um... é... de um só fornecedor. Porque na hora que veio a pandemia, eles começaram a vender pros meus clientes. Então fiquei sem ter o que vender. E aí eu comecei a fazer parceria com pessoas da Mantiqueira, né. Comecei a trabalhar com geleias de fora, né fazer parceria com outros fornecedores, [...]"

Apesar da queda nas vendas e da falta de produtos para abastecer a loja da cafeteria, esse fato motivou a gestora a buscar estratégias para direcionar o trabalho de vendas e fortalecimento da marca do café da empresa.

“Chacoalhou, pulou para fora o não era... não era enraizado da gente, e a gente acabou voltando nosso foco com o que a gente sabe fazer melhor, que é lidar com café, e vender nosso café, e toda xícara de café conta uma história, e é isso que a gente sabe fazer: contar nossa história através da nossa xícara, né”.

A gestora relatou que, boa parte do público consumidor de cafés na cafeteria, eram consumidores de outras cidades, pois o município de Santa Rita do Sapucaí, além de possuir uma faculdade de telecomunicações, possuiu muitas indústrias, então muitos que iam visitar a cidade, passavam por lá. E com a pandemia esse movimento caiu ainda mais.

Assim, a empresa começou a transformar os clientes do delivery como público alvo para adquirirem os cafés produzidos pela fazenda, a cada consumo da bebida, eles recebiam um cupom de desconto para comprar os pacotes de cafés torrados e moídos.

O delivery, segundo a gestão da cafeteria, é uma prestação de serviço que surgiu para ficar, pois para aqueles que estão se habituando a trabalhar em suas respectivas casas, continuarão a manter o consumo.

Outra estratégia adotada foi a forma de como as informações são lançadas nas redes sociais da empresa, antes da pandemia, as fotos e vídeos estavam mais atrelados aos produtos comercializados na loja, atualmente, o conteúdo lançado nas plataformas digitais está direcionado à origem dos cafés, como o trabalho é realizado para sua produção na lavoura e as formas de preparo.

Todas as estratégias adotadas pela cafeteria corroboram com as estratégias identificadas pelo Instituto de Economia Agrícola (2020), em que torrefadoras líderes do mercado, preocupadas com seus clientes institucionais, estão promovendo mecanismos de financiamento e oferecem suporte para o fluxo de caixa que foi contingenciado com a decretação da quarentena. Outras soluções, como os vouchers de compras antecipadas para utilização a posteriori, foram implementados (cafeterias, bares e restaurantes). A criatividade em marketing das marcas e negócios tem sido largamente empregada para manter a viabilidade econômica dos negócios.

Até o momento da entrevista, as vendas já estavam atingindo um nível até $35 \%$ do volume que era comercializado anteriormente, a procura pelo café aumentou, há expectativas de retomar a exportação do produto e o reconhecimento pela marca 
aumentou nesse período de pandemia em proporções muito maiores do que estava ocorrendo nos dois últimos anos. Então após as crises decorrentes da pandemia, fez com que a empresa buscasse focar e fortalecer seu próprio produto, pois diante da quantidade de fornecedores existentes, o desejo de promover os produtores locais e manter a cafeteria munida de produtos diferenciados, não dava a oportunidade de direcionar o trabalho exclusivamente para o café. Segundo a gestora:

“[...] as vendas caíram muito mesmo. E aí, isso serviu também para me ajudar a voltar o meu foco totalmente para o meu negócio. Meu negócio é café. Eu tava focada demais em ajudar as pessoas a ter os produtos, né. [...] Na hora que veio a pandemia, algumas pessoas não se importaram comigo como eu me importo com elas, então isso serviu pra eu entender que eu preciso primeiro me fortalecer."

No início da entrevista, a gestora narrou que o foco para vendas dos cafés estava direcionado para o mercado interno, mas diante da repercussão que a empresa está obtendo de seu novo trabalho para a promoção dos cafés, e como sua produção está direcionada ao mercado de cafés especiais, verifica-se o desejo de retomar a exportação. Para o Instituto de Economia Agrícola (2020), essa atitude é justificada pela possibilidade de que parte do volume de cafés especiais produzido pela fazenda possa ser comercializado como commodity, com a esperança de que seus investimentos sejam remunerados.

Com relação à formação de novas parcerias, a pandemia está promovendo novos tipos de alianças, como dito anteriormente, a empresa está buscando fornecedores da região, e, além disso, são os fornecedores que estão à procura de parceria com a cafeteria. Conforme opinião da gestora entrevistada, é um ponto muito positivo, pois a pandemia de uma certa forma, está promovendo a união de empresários que buscam apoio mútuo. Para ela:

"E cada vez mais e as parcerias que surgiram da pandemia, são parceiros que passaram pelo mesmo problema que a gente, e que não vieram atrás da gente visando uma vantagem e sim uma união, pra crescermos juntos. Eu gostei muito disso, sabe. Eu gostei muito! [...] porque normalmente a gente ia atrás das pessoas, a gente fazia proposta de parceria, gente vendia ideia, convencer a pessoa, agora não! Poxa! A gente é recebido, um convite para te conhecer, quero trabalhar com você, vamos unir nossas marcas! Ual! Que legal! Sempre sou eu que convido, eu fui convidada! Isso é muito legal! É uma surpresa, sabe?”

Por fim, uma nova organização na forma de servir cafés foi adotada em decorrência da pandemia, aumentando suas opções de serviços. Como a empresa precisou devolver dois imóveis que estavam sendo alugados, os materiais de um desses imóveis foi levado para a fazenda, se trata dos materiais do antigo lounge (lugar utilizado para servir cafés), com o objetivo de preparar cafés para os novos visitantes. Assim, os cafés que possuem um método de preparo que demanda maior tempo (chamado de slow coffee), serão realizados na fazenda, para que o visitante tenha oportunidade de apreciar melhor a bebida. Como explica a gestora:

\footnotetext{
“O que sobrou do lounge, nós montamos uma cafeteria na roça, na fazenda. [...] ]eu tinha 18 métodos de café na minha cafeteria, hoje eu devo ter uns seis. Eu levei todos os outros Slow Coffee, métodos que são feitos devagar de café, pra serem feitos devagar na fazenda, porque lá a gente tem mais tempo, [...] e a gente deixou os métodos mais rápidos na cafeteria pra otimizar e ter uma circulação maior das pessoas."
}

Verifica-se que a empresa sofreu grandes impactos financeiros com a pandemia, mas conseguiu adotar estratégias que estão promovendo sua permanência no mercado, aliadas à reorganização da estrutura, equipe de trabalho, formas de venda e divulgação do negócio. 


\subsection{Novas rotinas dos gestores}

A pandemia causou grandes alterações nas rotinas dos gestores da empresa analisada, tanto para o gestor da fazenda, quanto para a gestora da cafeteria.

Com o afastamento promovido aos funcionários da fazenda, o gestor precisou contratar novos empregados temporários, e mesmo com o retorno desses funcionários que permaneceram afastados, verificou-se que seus empenhos diminuíram bastante comparados aos demais.

Dessa forma, após o cumprimento do prazo de permanência na fazenda, contado em período igual ao do afastamento exercido pelos funcionários, seguindo as normas da MP 936 (Medida Provisória n 936, 2020), provavelmente haverá a demissão desses funcionários. Pois a atitude dos empregados fixos levou ao gestor da fazenda a reorganizar os prazos e a forma da colheita do café diferente do que são habitualmente realizados em outros anos, chegando ao ponto de assumir o trabalho operacional para que o café não corresse o risco de perder a qualidade da bebida. Segundo a observação dada pela gestora:

"A mão de obra parece que se acostumou a ficar de férias, que foram trabalhar pra outro lugar, fizeram dinheiro dobrado, e agora tão bem devagar mesmo. [...] eu colhi quase uma medida, e dois rapazes que tavam colhendo lá, colhendo uma medida o dia inteiro."

Outra alteração na rotina dos gestores foi que a pandemia oportunizou ao empreendimento a prestação de serviços voltados para a consultoria e cursos, muitas pessoas estão procurando a empresa para serem orientadas em como abrirem uma cafeteria ou para terem uma marca de café no mercado. Isso levou a empresa buscar apoio jurídico de como precificar esse tipo de prestação de serviço, segundo a gestora:

\footnotetext{
"Mas eu nunca tinha vendido esse serviço, aí com a pandemia, a procura cresceu tanto pra esse tipo de consultoria que eu tive que buscar um apoio jurídico e vender meu tempo, porque eu já não estou dando mais conta de atender todo mundo. [...] Principalmente nessa parte de auxiliar as pessoas que tão querendo montar o próprio negócio, o próprio negócio e torrar o próprio café, tem é muita gente procurando a gente pra poder industrializar, na industrialização do café." [...] As pessoas... eu tô sentindo que as pessoas tão querendo ter o próprio negócio, investir no próprio negócio, muita gente tomou um baque muito forte, perdeu emprego, e não quer mais ficar na mão das pessoas, né. E vender esse know how, isso que a gente aprendeu ao longo dos anos, né. Vender esse saber que a gente desenvolveu..."
}

\subsection{Pontos positivos e negativos causados pela pandemia}

Para concluir a entrevista, foi relatado pela gestora entrevistada o que ela considerava como ponto positivo e negativo em decorrência da pandemia.

Como pontos negativos, o acúmulo de trabalho durante esse período, provocou ansiedade na gestora. Além dos trabalhos desenvolvidos na empresa, vale destacar que a gestora é esposa, mãe e filha. Como relatado por ela mesma, no início da pandemia, foi necessário trazer o pai dela para morar junto a família devido à um problema de saúde e o apartamento que ele morava foi entregue ao dono do imóvel para economizar com o valor do aluguel, também a empregada foi suspensa do trabalho, então todas as atividades domésticas ficaram a cargo da gestora. E isso foi realizado juntamente com os serviços de atendimento e entrega da cafeteria:

"Então olha, no início, a minha funcionária não estava vindo, eu tive que trazer meu pai pra morar com a gente, entreguei o apartamento dele por economia, [...] ele tava meio doente, [...] eu fiquei sem empregada [...]. Com um monte de gente em casa né, então de manhã eu me dedicava a casa, e de tarde eu me dedicava ao café sozinha. Porque não tinha funcionário no café, estavam todos afastados. [...] Esse período pra mim foi o mais difícil, foi quando eu pedi 
ajuda do meu filho, assim, com o coração na mão, porque todo mundo falava: meu, cê tá botando seu filho em risco, mas como que eu vou fazer meu Deus do céu, não dou conta sozinha!!!”

O auxílio promovido aos funcionários também foi considerado como um ponto negativo, que levou a ausência no serviço e a queda no desenvolvimento do trabalho, do ponto de vista estratégico, segundo a gestora, esse auxílio deveria ser ofertado aos empregadores e não aos empregados.

Com o acúmulo de tarefas, um ponto positivo considerado pela gestora foi a motivação à organização do próprio trabalho, isso foi promovido devido a um curso realizado na pandemia sobre administração do tempo. Para ela:

\begin{abstract}
"Ao mesmo tempo, eu tinha feito um curso, com duas meninas [...] Elas deram um workshop de administração... como você administrar seu tempo [...]Foi a melhor coisa que eu fiz! Como eu usei nessa pandemia [...] Gente, eu tô botando muita coisa em dia! Eu tô botando muita coisa em dia. Minha vida tá em dia quase 100\%. Eu consegui no meio da pandemia me organizar. Isso é incrível!!! Eu fiquei feliz comigo mesma (risos)!!!’”
\end{abstract}

Outro ponto positivo foi a reorganização do trabalho e a oportunidade que a pandemia provocou para direcionar esforços no fortalecimento da marca de seus cafés. De acordo com o ponto de vista da gestora:

\begin{abstract}
"Então eu voltei o foco... sabe? Eu vou te falar que pandemia deixou a gente meio desorientado, mas hoje em dia eu acho que serviu pra... pra melhorar muita coisa. É como se fosse assim: é uma nova oportunidade de você recomeçar sabe? Você sabe... a gente chegou num limite de quase perder a loja, de quase perder, eu fechei o lounge, eu fechei meu escritório, eu tinha três aluguéis, eu tô com um. Eu enxuguei minha operação, eu enxuguei o quadro de funcionários, não por vontade própria, né. Mas isso deu oportunidade da gente se reorganizar, a se reestruturar e se reinventar. [...] Então para mim, na marca... a pandemia tá sendo muito benéfica. Porque ela tá me dando a oportunidade, me deu oportunidade de me dedicar mais a marca."
\end{abstract}

Esse trecho acima corrobora com Moutinho \& Conti (2016) em afirmar que a narrativa pessoal é o resultado de um recurso aos discursos ou narrativas sociais dominantes e também, o processo no qual essas mesmas narrativas sociais são progressivamente reconstruídas no plano das relações sociais. A pandemia trouxe uma ressignificação do trabalho, da cafeteria e da marca da empresa para os gestores, ao ponto de perceber que o café que é o "carro chefe" do negócio, não estava sendo até então tratado como foco principal.

Por fim, outro ponto positivo é a valorização do negócio dada pelos clientes durante essa pandemia. Como observado pela gestora:

"E o pessoal começou a dar muito mais valor na gente sabe, ter mais respeito pelo o nosso trabalho, procurar mais a gente, parabenizar a gente. Eles querem ver a gente... me pedindo... O pessoal... eu vejo que tem muito mais visualização no Instagram quando eu gravo."

Esse sentimento de valorização narrado pela gestora pode ser justificado pela afirmação de Lhuilier (2020), a categoria reconhecida como os "sobrecarregados de trabalho", não confinados e expostos: cuidadores, trabalhadores de manutenção, assistentes sociais, caixas, entregadores, caminhoneiros, coletores de lixo, carteiros, agricultores, educadores, bombeiros, militares, policiais... ou seja, todos aqueles que prestam serviço de maneira que o confinamento de alguns se torna possível a partir do trabalho de outros, agora são o centro das atenções, pois a sociedade descobriu que suas atividades, frequentemente invisibilizadas, desvalorizadas, mal pagas, são, atualmente, reconhecidas como "essenciais" à vida. 


\section{Conclusão}

A entrevista narrativa proporcionou atingir o objetivo dessa pesquisa que foi investigar os efeitos da pandemia do COVID-19 no sistema de produção e comercialização de café cultivado por uma empresa familiar do setor cafeeiro instalado no município de Santa Rita do Sapucaí, Minas Gerais. Foi possível explorar todos os caminhos que a empresa vem percorrendo e quais foram os resultados advindos desse processo.

Conclui-se que os gestores do empreendimento estão adotando de maneira regular as técnicas de prevenção do COVID19. Como ponto negativo, apesar da institucionalização da MP 936, para apoiar a mão de obra trabalhista, neste estudo, o benefício não surtiu efeitos. Em contrapartida, pode-se caracterizar como pontos positivos, a pandemia direcionou os gestores a focarem seus trabalhos naquilo que pode ser considerado como carro-chefe do negócio: o café, fortalecendo a marca, adotando novas técnicas de vendas, divulgação do produto, promovendo consultorias e por último, a pandemia provocou um novo arranjo de parcerias tanto entre as pessoas envolvidas no sistema de produção do café na fazenda, quanto novos fornecedores para a cafeteria.

A narrativa proporcionou segmentar a empresa rural em dois paralelos, os negócios que são desenvolvidos no meio rural e fora do meio rural. No meio rural a empresa: produz cafés, realiza torrefação própria, presta serviço de pós colheita e torração de cafés para terceiros, possui cozinha para geração de cursos e locação para produção de terceiros, turismo rural.

Negócio fora do meio rural: cafeterias, coffee bikes, comercialização de cafés especiais, tradicionais e commoditie, produção e comercialização de produtos à base de café, comercialização de produtos confeccionados por produtores da região, cursos e consultoria.

Sugere-se que novos estudos sejam realizados em demais empresas do setor cafeeiro e de outros segmentos agropecuários para que novas estratégias sejam identificadas e sirvam de suporte para aquelas empresas que estejam enfrentando dificuldades para superar a crise imposta pelo Novo Coronavírus.

\section{Referências}

Baron, M. V., Santos, M. P., Isa, C. P. M., Santos, A. C., Marangoni, C., Werle, T. M., \& Costa, B. E. P. (2020). Contenção, mitigação e supressão no combate à pandemia do COVID-19: Levantamento e análise. Saúde Coletiva, 10(54), 2652-2659.

Barros, A. (2020). PIB tem queda recorde de 9,7\% no $2^{\circ}$ trimestre, auge do isolamento social. Agência IBGE Notícias. https://agenciadenoticias.ibge.gov.br/agencia-noticias/2012-agencia-de-noticias/noticias/28720-pib-tem-queda-recorde-de-9-7-no-2-trimestre-auge-doisolamento-social

Bauer, M. W., Gaskell, G. (2011). Pesquisa Qualitativa com texto, imagem e som: Um manual prático (9a ed.). Vozes.

Borém, F. M. (2008). Pós-colheita do café. UFLA.

Cappelle, M. C. A., Melo, M. C. O. L., \& Gonçalves, C. A. (2003). Análise de conteúdo e análise de discurso nas ciências sociais. Organizações Rurais \& Agroindustriais - Revista Eletrônica de Administração da UFLA, 5(1), 1-15.

Centro de Operações de Emergência em Saúde Pública. (2020, April 6). Especial: doença pelo Coronavírus 2019. Boletim Epidemiológico, 7, 1-28. https://portalarquivos.saude.gov.br/images/pdf/2020/April/06/2020-04-06---BE7---Boletim-Especial-do-COE---Atualizacao-da-Avaliacao-de-Risco.pdf

Decreto legislativo $n^{\circ}$ 6, de 20 de março de 2020 (2020, 20 março). Reconhece, para os fins do art. 65 da Lei Complementar $n^{\circ} 101$, de 4 de maio de 2000, a ocorrência do estado de calamidade pública, nos termos da solicitação do Presidente da República encaminhada por meio da Mensagem $n^{\circ} 93$, de 18 de março de 2020 .

Instituto Brasileiro de Geografia e Estatística. (2020, September 1). Contas Nacionais Trimestrais: $2^{\circ}$ trimestre de 2020. https://agenciadenoticias.ibge.gov.br/media/com_mediaibge/arquivos/330b1f2240a851ff4ddf8413ec31ec19.pdf

Instituto de Economia Agrícola. (2020). Mercado de Café - Covid-19. Análise e Indicadores do Agronegócio, 15(6).

International Coffee Organization. (2020a). Impact of covid-19 on the global coffee sector: The demand side. ICO Coffee Break Series, 1.

International Coffee Organization. (2020b). Volatile coffee prices: Covid-19 and market fundamentals. ICO Coffee Break Series, 2.

Lhuilier, D. (2020). E se essa crise mudasse radicalmente o mundo do trabalho... Caderno de Administração, 28, 89-84. 
Research, Society and Development, v. 10, n. 14, e152101421757, 2021

(CC BY 4.0) | ISSN 2525-3409 | DOI: http://dx.doi.org/10.33448/rsd-v10i14.21757

Medida Provisória ${ }^{\circ}$ 936, de $1^{\circ}$ de abril de 2020 (2020, 1 abril). Institui o Programa Emergencial de Manutenção do Emprego e da Renda e dispõe sobre medidas trabalhistas complementares para enfrentamento do estado de calamidade pública reconhecido pelo Decreto Legislativo $\mathrm{n}^{\circ} 6$, de 20 de março de 2020 , e da emergência de saúde pública de importância internacional decorrente do coronavírus (covid-19), de que trata a Lei no 13.979, de 6 de fevereiro de 2020, e dá outras providências.

Menocci, A. (2020). Conheça o cáscara. O chá feito com o fruto do café. Barista Wave. https://baristawave.com/cascara-cha-do-fruto-do-cafe/

Minayo, M. C. S. (2000). O desafio do conhecimento: pesquisa qualitativa em saúde (7a ed.). Hucitec.

Ministério da Saúde. (2020a). Coronavírus COVID-19. O que você precisa saber. https://coronavirus.saude.gov.br/

Ministério da Saúde. (2020b). Painel Coronavírus. https://covid.saude.gov.br/

Moutinho, R., \& Conti, L. (2016). Análise narrativa, construção de sentidos e identidade. Psicologia: Teoria e pesquisa, 32(2), 1-8.

Muylaert, C. J., Sarubbi, V., Jr., Gallo, P. R., Rolim Neto, M. L., \& Reis, A. O. A. (2014). Entrevistas narrativas: Um importante recurso em pesquisa qualitativa. Revista da Escola de Enfermagem da USP, 48(2), 193-199.

Organização Pan-Americana da Saúde. (2020). Folha informativa sobre COVID-19. https://www.paho.org/pt/covid19

Serviço Nacional de Aprendizagem Rural. (2020). Coronavírus: Recomendações de prevenção nas propriedades rurais. Senar. https://www.cnabrasil.org.br/assets/images/Guia-COVID-Diagramado-v4-corrigido-1.pdf

Silva, C. M., Soares, R., Machado, W., \& Arbilla, G. (2020). A pandemia de COVID-19: Vivendo no Antropoceno. Revista Virtual de Química, 12(4), 1-16.

Sistema Mineiro de Inovação. (2020). SIMI lança mapeamento de soluções inovadoras contra o COVID-19. SIMI Notícias. http://www.simi.org.br/noticia/SIMIlanca-mapeamento-de-solucoes-inovadoras-contra-o-COVID-19.

Uol (2020). De cada 10 empresas que fecharam no país, 4 foram afetadas pela pandemia. UOL Economia. https://economia.uol.com.br/noticias/redacao/2020/07/16/ibge-covid-empresas.htm

Zaccarelli, L. M., \& Godoy, A. S. (2013). “Deixa eu te contar uma coisa...”: Possibilidades do uso de narrativas e sua análise nas pesquisas em organizações. Revista Gestão Organizacional, 6(3), 25-36. 